\title{
O Conceito de Paranoia em Freud
}

\author{
The Freudian Concept of Paranoia \\ El Concepto de Paranoia en Freud
}
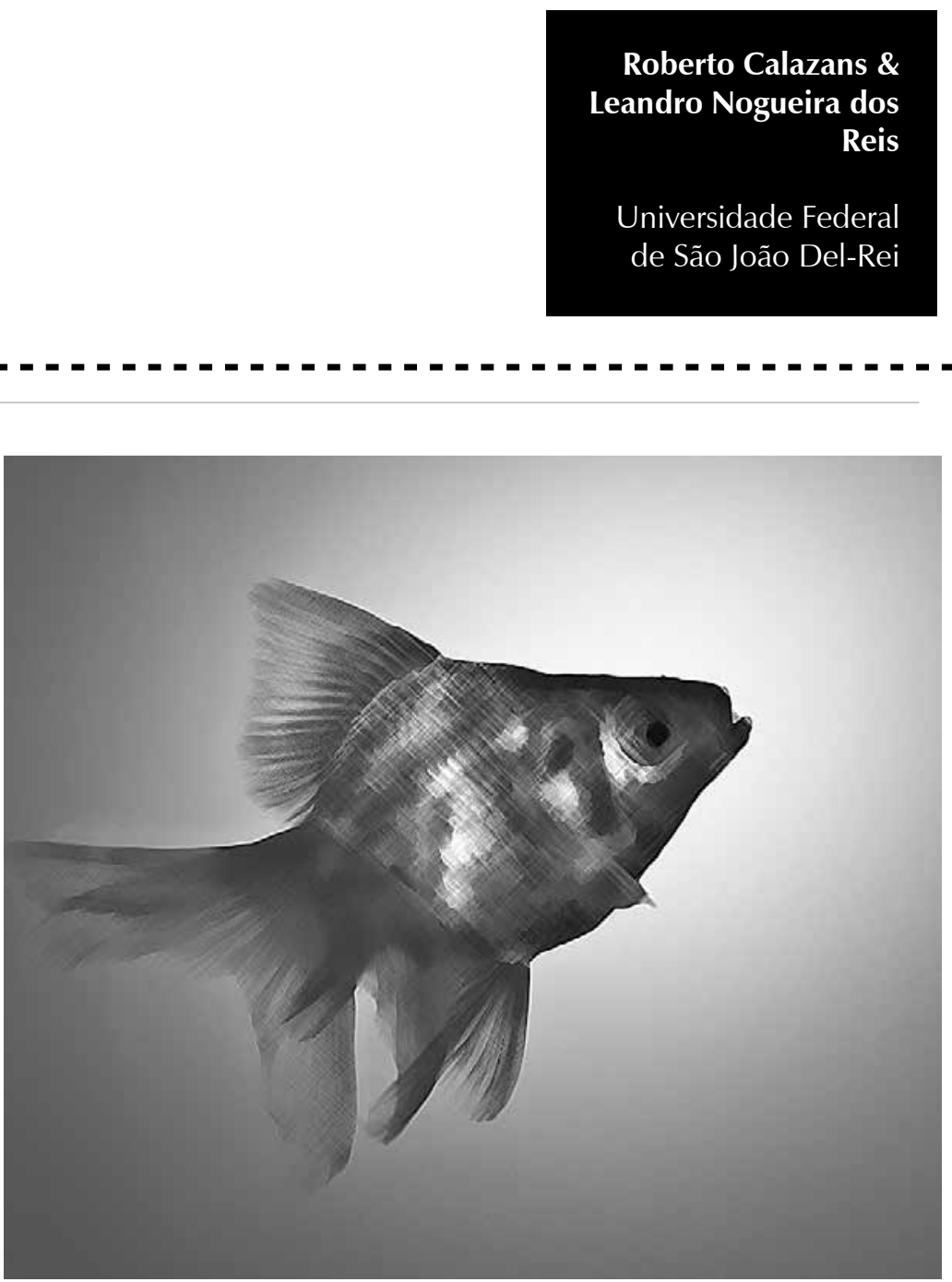
Resumo: Neste artigo, refazemos o percurso freudiano a propósito do conceito de paranoia em sua obra. Esse percurso se fará a partir dos textos considerados pré-psicanalíticos, passando por aquele que é considerado o texto maior de Freud sobre as psicoses (o Caso Schereber), culminando com suas análises que levam em consideração sua segunda teoria sobre o funcionamento psíquico e sobre o conflito pulsional. Nosso objetivo é demonstrar como Freud, em sua elaboração das questões relativas à psicose, e à paranoia, mais especificamente, jamais se furtava a encarar os desafios que a clínica impunha. E por não recuar frente a esses desafios é que a sua própria teoria vai se formulando, em uma relação dialética entre os impasses da prática e a necessidade de estabelecer um rigor teórico. O artigo trata, também, da forma como o rigor teórico permite o estabelecimento de um diagnóstico diferencial entre neurose e psicose, além de assentar as bases para que os psicanalistas pós-freudianos pudessem pensar em um direcionamento para tratar a psicose.

Palavras-chave: Psicanálise. Paranoia. Freud, Sigmund, 1856-1939. Teoria psicanalítica.

Abstract: In this article we retrace the route in regard to the Freudian concept of paranoia in his work. This route will be considered from the pre-psychoanalytical texts, through which is considered the greatest of Freud's text psychosis (Case Schereber), and culminating in his analysis that take into account his second theory of the psychic functioning and the conflict drives. Our goal is to demonstrate how Freud, in his elaboration of the issues related to psychosis, and paranoia, more specifically, never avoids to face the challenges imposed by the clinic. And for not setting back to these challenges is that his theory will be formulated in a dialectical relationship between the dilemmas of practice and the need to establish a theoretical rigor. This theoretical rigor allows the establishment of a differential diagnosis between neurosis and psychosis as well as lays the groundwork so that post-freudian psychoanalysts could think of a direction for the treatment of psychosis.

Keywords: Paranoia. Psychoanalysis. Freud, Sigmund, 1856-1939. Psychoanalitical theory.

Resumen: En este artículo volver sobre la ruta en relación con el concepto freudiano de la paranoia en su trabajo. Esta ruta se considerará a partir de los textos pre-psicoanalítica, a través de lo que esconsiderado el más grande de la psicosis el texto de Freud (el caso Schereber ) y que culminó en su análisis teniendo en cuentasu segunda teoría del funcionamiento psíquico y el conflictounidades. Nuestro objetivo es demostrar cómo Freud, en suelaboración de las cuestiones relativas a la psicosis, paranoia, y más en concreto, nunca tímido para enfrentar los desafíosimpuestos por la clínica. ¿Y por qué no se establece de nuevo a estos desafíos es que su teoría se formulará en una relación dialéctica entre la práctica y los dilemas de la necesidad de establecer un rigor teórico. Y como esta el rigor teórico permite el establecimiento de un diagnóstico diferencial entre neurosis y psicosis, así como sentar las bases para los psicoanalistaspost-freudianos podría pensar una dirección para el tratamiento de la psicosis.

Palabra-Clave: Paranoia. Psicoanalísis. Freud, 1856-1939. Teoria psicoanalítica.

Este artigo tem por objetivo apresentar o conceito de paranoia em Freud. Fizemos um breve apanhado das nosografias utilizadas por Freud e das diversas formas de agrupamento em que estas foram dispostas no decorrer de sua obra. Esse apanhado permitiu-nos situar a paranoia, em um primeiro momento, como uma modalidade específica de neuropsicose de defesa, e em segundo, dentro do quadro das psicoses ou daquilo que Freud chama, algumas vezes, de neurose narcísica, outras, de parafrenias. Consideramos essa contextualização necessária devido ao caráter dinâmico da teoria freudiana e por nos permitir distinguir a paranoia das demais afecções, circunscritas ou não ao campo das psicoses.

\section{Distinções gerais entre neurose e psicose na fase pré- psicanalítica de Freud}

Uma característica marcante na obra de Freud, ainda mais para o leitor que se preocupa com as modificações feitas no decorrer do tempo e sabe que em nenhum texto a teoria se encontra acabada, é o modo como a preocupação com a histeria o leva a formular, a partir da clínica, a teoria psicanalítica. Antes de esta se constituir como tal, temos uma fase pré-psicanalítica que apresenta fortes elementos naturalistas, derivados de uma formação fisicalista de Freud, que gradualmente vão sendo superados. 
Essa superação se encontra também na abordagem nosográfica de Freud. Tomemos, por exemplo, a primeira nosografia propriamente freudiana, que é aquela que se situa entre neuroses atuais e neuroses de defesa. As primeiras se definem como resultado direto da inadequação ou da ausência de satisfação sexual no sentido genital do termo. As neuroses de defesa, por sua vez, possuem uma importância fundamental para a psicanálise, pois, ao afirmar que a defesa incide sobre uma representação incompatível, e ao situar o fracasso da defesa como a gênese da neurose, Freud coloca o problema do recalque - e, em consequência, daquilo que é o inconsciente freudiano - no cerne de suas investigações. Devemos ressaltar ainda que, embora nesse período os termos neurose e psicose estejam presentes, eles ainda não possuem o sentido que assumirão posteriormente, mas são utilizados no sentido corrente na época: uma distinção entre afecções que não teriam uma causa biológica conhecida (neurose) daquelas cuja causalidade é considerada biológica (psicose).

Temos então, nessa época, a seguinte distinção freudiana: de um lado, as neuroses atuais (neurose de angústia e neurastenia) resultantes da ausência ou da inadequação de satisfação sexual, encaradas como algo estritamente somático, e, de outro, as neuroses de defesa, que, por incidirem sobre uma representação, apontam uma excitação marcadamente psíquica. Entre as chamadas neuroses de defesa, Freud aborda, além das principais que são a histeria, a neurose obsessiva, e a paranoia, outras afecções como a confusão alucinatória e as psicoses histéricas.

Notemos, entretanto, que, com o decorrer do tempo, a distinção entre neurose atual e neurose de defesa vai perdendo sua importância. Em Análise Terminável e Interminável, Freud afirmará que "a etiologia de todo distúrbio neurótico é, afinal de contas, uma etiologia mista" (1937/1996, p.251), pois depende tanto da força constitucional da pulsão quanto dos efeitos traumáticos e da sua relação com as representações. Ainda no período pré-psicanalítico, o termo misto neuropsicose aparece no título de dois de seus principais trabalhos: As Neuropsicoses de Defesa (1894/1996) e Observações Adicionais sobre as Neuropsicoses de Defesa (1896/1996). Por esse motivo, antes de prosseguirmos na questão nosográfica, gostaríamos de ressaltar que, por mais que Freud vá aos poucos abandonando uma linguagem biológica e passe a privilegiar o psiquismo, em suas novas formulações, os aspectos somáticos inerentes ao sujeito não são deixados de lado, mas subvertidos pela teoria das pulsões. Podemos nos remeter, para destacar essa questão, à definição feita por Freud em Pulsões e Destinos da Pulsão, em que esta se apresenta como "um conceitolimite entre o psíquico e o somático" ou como o "representante psíquico dos estímulos que provêm do interior do corpo e alcançam a psique" (1915/2004a).

Na época em que a distinção se dá entre neuroses atuais e neuroses de defesa, já é possível encontrar um elemento que revela o futuro conceito de psicose. Trata-se da utilização, por parte de Freud, do termo verwerfung, ou mais precisamente, do termo verwirft, que aparece pela primeira vez em As Neuropsicoses de Defesa. Segundo Freud, nos casos de histeria e de neurose obsessiva, a defesa contra a representação incompatível consiste em separar o afeto da representação; dessa forma, a representação permaneceria na consciência, ainda que enfraquecida e isolada. Por outro lado, ao se referir a um caso de confusão alucinatória, Freud nos fala de uma defesa muito mais poderosa e bem sucedida: "nela o eu rejeita (verwirft) a representação incompatível juntamente com seu afeto, e comporta-se como se a representação jamais lhe tivesse ocorrido" 
(1894/1996, p. 64). Tanto Maleval (2002, p. 37) quanto Simanke (1994, p. 77) citam essa passagem, destacando o termo alemão utilizado por Freud, e reconhecem-na como a primeira passagem em que a verwerfung aparece com o sentido privilegiado por Lacan ao formular o conceito de foraclusão do Nome do Pai - conceito que visa a cumprir a expectativa freudiana e estabelecer um mecanismo de defesa específico da psicose.

No que diz respeito especificamente à paranoia, notemos que a primeira vez que esta aparece em Freud - Rascunho H (1895/1996a) - ele a situa como diametralmente oposta à confusão alucinatória, inclusive agrupandoas sob a mesma categoria, como psicoses de desafio ou de oposição. Essa relação estabelecida entre paranoia e confusão alucinatória, ao mesmo tempo em que nos remete a uma semelhança entre seus mecanismos de defesa, permite-nos pensar sobre a diferença com os mecanismos histérico e obsessivo.

\section{Breve distinção entre a paranoia e as demais neuropsicoses}

Em As Neuropsicoses de Defesa, assim como nas Observações Adicionais sobre as Neuropsicoses de Defesa, Freud trata de uma terceira afecção além da histeria e da neurose obsessiva. Em 1894, essa terceira afecção se refere à confusão alucinatória, e, no segundo, à paranoia. $\mathrm{O}$ interessante é que ambas apresentam uma modalidade especial de processo defensivo. Como aponta Simanke: nelas "os termos envolvidos no processo defensivo são os mesmos - eu, representação, e afeto -, mas a dinâmica envolvida em suas inter-relações é bastante distinta da que ocorre na histeria e nas obsessões" (1994, p. 79). Façamos então um paralelo e vejamos, primeiro na confusão alucinatória e depois na paranoia, em que consiste tal distinção.
Na confusão alucinatória, o eu rejeita tanto a representação quanto o afeto, como se eles nunca tivessem existido. Nesse caso, a especificidade do mecanismo de defesa consiste em ser muito mais poderoso, pois rechaça completamente a representação incompatível. Ao descrevê-lo, Freud afirma: "o eu rompe com a representação incompatível; esta, porém, fica inseparavelmente ligada a um fragmento da realidade, de modo que, à medida que o eu obtém esse resultado, também ele se desliga, total ou parcialmente, da realidade" (1894/1996, p. 65). É a partir da ligação entre representação incompatível e o que Freud denomina realidade que se explica a alucinação. Devido ao fato de ambas serem rechaçadas pela defesa, as representações do sujeito recebem a vividez das alucinações nos casos de confusão alucinatória. Sendo assim, se a defesa é bem sucedida, a alucinação pode ser encarada como um reforço da defesa.

Nesse ponto, nós nos deparamos com uma questão relevante para pensarmos sobre a especificidade desse mecanismo de defesa. O modo como Freud descreve a alucinação na confusão alucinatória coincide com a teoria da alucinação esboçada na primeira parte do Projeto para uma Psicologia Científica (1895/1996). Em ambos os casos, a alucinação consiste na realização de desejos - afirmação válida também para as alucinações histéricas e para os sonhos - porém devemos considerar que, se nos sonhos e na histeria a alucinação se manifesta como o retorno do recalcado, na confusão alucinatória, a alucinação é descrita como aquilo que mantém o recalcado o mais afastado possível. Além disso, uma vez que a defesa na confusão alucinatória é mais bem sucedida, rechaçando a representação juntamente ao seu afeto, não há como falarmos de fracasso da defesa.

Notemos que Freud define as entidades clínicas segundo o modo como o fracasso da defesa se expressa. Na histeria, a 
representação conflitiva é despojada do seu afeto, ficando impedida de se associar com outras representações. Em contrapartida, esse afeto encontra outro destino, e é transformado em uma inervação somática denominada por Freud conversão. $\mathrm{Na}$ obsessão, os processos observados são, até certo ponto, os mesmos, porém o afeto dissociado da representação conflitiva se liga a outras representações que, em si mesmas, não são conflitivas, mas que devido a essa falsa ligação ou deslocamento se tornam representações obsessivas. Tanto na histeria quanto nas obsessões, o mecanismo de defesa e seu fracasso envolvem ao menos duas representações. Podemos abordá-las ao modo como Freud o fez no Projeto de uma Psicologia Científica: a representação B seria a representação inconsciente recalcada inicialmente, e a representação A seria a representação pré-consciente para a qual o afeto se desloca quando do fracasso da defesa. Esse complexo formado por A + B diz respeito ao que Freud denomina a formação de símbolos, e, ao menos nas neuroses histéricas e obsessivas, é um dos fatores primordiais na constituição do sintoma.

Por motivos de clareza, cabe fazer uma breve distinção entre a formação de compromisso e a formação de símbolos. No Rascunho $K$, ao se referir à neurose obsessiva, Freud afirma que, no retorno do recalcado, a autocensura retorna inalterada, e por certo tempo emerge simplesmente como um sentimento de culpa sem conteúdo. Devemos considerar, entretanto, que, com o tempo, "ela vem a se ligar a uma representação que é distorcida de duas maneiras - no tempo e no próprio conteúdo" (1896/1996, p. 271). Distorcida no tempo porque se refere a uma ação contemporânea ou futura, e não à dita experiência primária, e no conteúdo porque não se refere a essa experiência, mas é escolhida a partir de algo que lhe é análogo dentro da mesma categoria, isto é, ocorre uma substituição. Essa dupla distorção, que ocorre no deslocamento do afeto de uma representação incompatível para uma inócua, é o que caracteriza a formação de compromisso na histeria e na obsessão, e diz respeito à própria formação de símbolo. Ela nos permite pensar na expressão antes utilizada por Freud para se referir ao deslocamento: a de falsa ligação. Se ela é falsa devido ao deslocamento cronológico e à substituição por analogia, cabe frisar que, no que diz respeito ao afeto e à categoria da representação, ela é verdadeira, e é nisso que consiste sua função na formação dos sintomas. Podemos afirmar que, se na histeria e na obsessão a formação de compromisso se dá por meio da formação de símbolo, a formação de compromisso de modo geral - pois não ocorre somente nos sintomas histéricos e obsessivos - possui um sentido mais amplo que a formação de símbolo.

Vejamos, agora, de que modo essas questões sobre a formação de compromisso, formação de símbolos e fracasso da defesa podem contribuir para a discussão sobre a paranoia. Considerando que as afecções acima citadas possuem mecanismos de defesa específicos, cujo fracasso se dá de forma distinta, um aspecto que devemos considerar para pensar na diferença entre paranoia e nas demais neuropsicoses é a formação dos sintomas. No Rascunho K, Freud sustenta que a formação dos sintomas - seja na neurose obsessiva, seja na paranoia ou na histeria - envolve uma formação de compromisso entre a autocensura e a lembrança de uma experiência primária prazerosa. Essa formação de compromisso se dá após um período bem sucedido de defesa, ou no estágio do retorno do recalcado. Contudo, se considerarmos que na confusão alucinatória a defesa não fracassa, não há como falarmos de um retorno do recalcado nem tampouco de formação de compromisso ou de símbolo.

Eis aí a questão: se no Rascunho $K$ Freud afirma que na neurose obsessiva, na paranoia, 
e na histeria a formação de compromisso constitui o sintoma, não podemos perder de vista que, na paranoia, diferentemente do que ocorre nas demais, a formação de compromisso não implica a formação de símbolo. Nela não ocorre o deslocamento de afeto da representação recalcada para outra da mesma categoria, ou seja, não há a substituição em que $A$ se torna símbolo de B. Segundo Freud, na paranoia, "a defesa fracassa por completo, e a autoacusação original, o termo real do insulto de que o sujeito vinha tentando poupar-se retorna em sua forma inalterada" (1896/1996, p. 171). Se na paranoia o recalcado retorna de forma inalterada, é porque não houve substituição de representações, nem tampouco a dupla distorção acima citada. Nela também há um esquecimento ou perda de referência, porém as causas que a determinam são diferentes; se na histeria essa perda se deve à formação de símbolos, na paranoia, ela se deve à modificação da fronteira entre o eu e o exterior e à distorção temporal. No caso de paranoia descrito nas Observações Adicionais sobre as Neuropsicoses de Defesa, essa forma de distorção se torna bem clara, e ele mostra como as alucinações da sra. P. eram representações de experiências da infância que retornavam com o mesmo conteúdo em uma época posterior.

As considerações até aqui traçadas a respeito da confusão alucinatória e da paranoia nos permitem, por um lado, apontar semelhanças entre elas, e por outro, apontar os traços que as distinguem da histeria e da obsessão. Além disso, a ausência da formação de símbolo na paranoia e na confusão alucinatória traz elementos fundamentais para se pensar sobre os futuros desenvolvimentos da teoria das psicoses. Desde as Observações Adicionais sobre as Neuropsicoses de Defesa, Freud situa a projeção como o mecanismo de defesa específico da paranoia. Entretanto, se na confusão alucinatória Freud destaca o êxito da defesa, no que se refere à paranoia, ele fala de um fracasso radical, pois aquilo que o sujeito rechaçou retorna de forma inalterada. Além disso, devemos atentar para o modo como se dá tal retorno - o que permite a Freud falar de projeção: na paranoia, o que foi rechaçado retorna na forma de alucinações, como veremos a seguir, como se proviessem de fora.

\section{Novas contribuições a respeito da paranoia}

Em Notas Psicanalíticas sobre um Relato Autobiográfico de um Caso de Paranoia (1911/1996), popularmente conhecido como Caso Schreber, Freud escreve uma frase que ficou famosa na história da psicanálise em relação às psicoses: "Foi incorreto dizer que a percepção suprimida internamente é projetada para o exterior; a verdade é, pelo contrário, como agora percebemos, que aquilo que foi internamente abolido retorna de fora" (1911/1996, p. 78). Além de tornar mais claro o modo como se dá o fracasso da defesa na paranoia, esse texto permite compreender o mecanismo que a determina; permite, também, compreender várias afirmações feitas por Freud nos textos anteriores em que trata da paranoia, dando consistência teórica ao que anteriormente havia sido apenas observado.

No Rascunho K, Freud havia situado a projeção como consequência das alterações que ocorrem nos limites do eu com o mundo externo. Além disso, havia denominado melancolia o processo que leva a um empobrecimento do eu, e de delírio de grandeza aquele pelo qual o eu tem seus limites exageradamente expandidos. Com as novas contribuições trazidas pelo Caso Schreber, podemos pensar sobre essas alterações nos limites do eu, assim como seu inchaço ou empobrecimento, a partir do conceito de narcisismo. Este é definido por Freud como um estádio intermediário entre o autoerotismo e o amor objetal. As pulsões 
que até então permaneciam empenhadas em atividades autoeróticas - estreitamente vinculadas às zonas erógenas - como précondição para estabelecerem um objeto amoroso unificado, começam a tomar o próprio corpo como objeto, sendo apenas posteriormente que passam daí à escolha de um objeto externo. Assim, o eu é situado como o reservatório de libido a partir do qual esta é direcionada para os objetos, e para o qual esse investimento volta na paranoia.

O conceito de narcisismo possui um papel fundamental no desenvolvimento da teoria psicanalítica das psicoses: foi por meio dele que Freud formulou a categoria das neuroses narcísicas, a partir da qual se origina, pelo menos em parte, a categoria psicanalítica das psicoses. Cabe frisar que, embora a expressão neurose narcísica tenha tido uma existência efêmera, sua importância consiste em ser uma categoria genuinamente freudiana, fundamentada em um conceito recém-forjado por Freud, e em abarcar mais ou menos completamente o que mais tarde será denominado psicose.

O texto de 1911 nos permite compreender observações realizadas em textos anteriores, como, por exemplo, a relação entre a alucinação e o delírio. No Rascunho K, Freud se estende sobre as alucinações e os delírios na paranoia, e suas relações com a defesa. Ele situa o delírio de observação, juntamente às alucinações táteis, visuais e auditivas, como sintomas do retorno do recalcado. Por outro lado, ele fala de outro tipo de delírio, que são os delírios de assimilação ou interpretativos. Em consequência do estranhamento causado pelo retorno da representação incompatível, uma vez que a defesa paranoica leva o sujeito a considerar esse conteúdo como algo externo, o eu tenta explicá-lo através do delírio. Este, por sua vez, é responsável pelas profundas modificações que ocorrem no eu, e que se articulam com a afirmação feita no Rascunho $H$, de que os paranoicos amam tanto seus delírios como a si mesmos. A partir dessas modificações, o eu se transforma em um eu delirado, em que o delírio é idêntico ao si mesmo, por isso, o paranoico só reconhece como próprio aquilo que emerge do delírio. Podemos constatar, a partir dessa acepção do delírio, que já nessa época ele assume o caráter de uma tentativa espontânea de cura, o que só é explicitado em 1911.

\section{Paranoia e fixação narcísica}

No Caso Schreber, Freud divide o processo de defesa em três fases distintas: fixação, recalque propriamente dito e fracasso da defesa. A primeira consiste em uma fixação que "é a precursora e condição necessária para todo recalque" (1915/2004b). Nela um determinado componente da pulsão deixa de acompanhar os demais ao longo do desenvolvimento, e, em consequência, é deixado para trás em um estádio infantil. Essa primeira fase do recalque coincide com o que Freud definirá, no texto O Recalque (1915/2004), como recalque primordial ou primário. Além disso, em ambos os textos, Freud destaca a primeira fase como a base determinante para as etapas posteriores, que são: o recalque propriamente dito e seu fracasso. Dessa forma, podemos destacar a importância estrutural assim como o caráter determinante que ela possui na teoria freudiana. O recalque primário "consiste em interditar ao representante psíquico da pulsão a entrada e admissão no consciente" (1915/2004b, p.178), e, portanto, possui um papel fundante na constituição do inconsciente.

Também no Caso Schreber (1911/1980), assim como em $O$ Recalque, Freud contrapõe o aspecto passivo apresentado pelo recalque primário ao aspecto ativo apresentado pelo recalque secundário. Essa atividade proviria dos sistemas mais desenvolvidos do eu, e entraria em ação sempre que alguma tendência psíquica entrasse em conflito 
Segundo Freud, para que 0 recalque fosse levado a cabo, seria necessário, além do movimento de repulsa que parte do eu, um movimento de atração exercido pelo representante inconsciente da pulsão. A "tendência ao recalque não realizaria seu intento se essas forças não atuassem em conjunto, se não existisse algo antes recalcado e pronto para acolher 0 que foi repelido do consciente" (1915/2004b, p. 179). com o eu. Entretanto, Freud destaca que só o conflito, ou a aversão despertada no eu por tais tendências, não seria suficiente para conduzir ao recalque, ponto que nos proporciona maior clareza dos processos inconscientes e de seu caráter dinâmico. Segundo Freud, para que o recalque fosse levado a cabo, seria necessário, além do movimento de repulsa que parte do eu, um movimento de atração exercido pelo representante inconsciente da pulsão. A "tendência ao recalque não realizaria seu intento se essas forças não atuassem em conjunto, se não existisse algo antes recalcado e pronto para acolher o que foi repelido do consciente" (1915/2004b, p.179).

Freud também destaca o papel exercido pelo recalque primário sobre o fracasso da defesa. Esta, no que diz respeito aos fenômenos patológicos, é a fase mais importante, pois é a partir dela que se formam os sintomas. Ela "toma seu impulso do ponto de fixação, e implica uma regressão do desenvolvimento libidinal e esse ponto" (1911/1996, p.75). Se, por um lado, essa relação de determinação - que a fixação mantém com as demais fases - é válida para qualquer afecção, por outro lado, não podemos esquecer que o que distingue uma afecção da outra é o ponto em que, na história de cada sujeito, vai ocorrer a fixação da libido. No caso da paranoia, esse ponto de fixação se situa no estádio do narcisismo primário. Sendo assim, é a partir dele que devemos considerar o mecanismo de defesa, assim como a formação dos sintomas. Segundo Freud, embora na paranoia a libido seja retirada dos objetos, esse desligamento não é exclusivo da paranoia, mas uma característica regular em qualquer mecanismo de defesa. Não obstante, algo nos permite distinguir o desligamento paranoico do ocorrido nas demais afecções. Se na histeria "a libido liberada transforma-se em inervações somáticas ou em ansiedade" (1911/1996, p.79), na paranoia, ela "vincula-se ao eu e é utilizada para o engrandecimento deste" (1911/1996, p.79). Esse destino da libido explica o caráter megalomaníaco presente na maioria dos casos de paranoia. "Faz-se assim um retorno ao estádio do narcisismo, no qual o único objeto sexual de uma pessoa é seu próprio eu" (1911/1996, p.79). Esse retorno ao narcisismo é denominado por Freud narcisismo secundário. Há, além disso, outra observação que nos permite pensar na fixação narcísica na paranoia em relação às etapas posteriores do processo de defesa.

De acordo com Freud, no Caso Schreber, assim como em vários outros analisados por ele, por Jung, por Sándor Ferenezi e por alguns outros psicanalistas da época, constatou-se que, no centro do conflito subjacente à paranoia, pôde ser identificada uma defesa contra o desejo homossexual. Atentemos, portanto, para a ideia de que o papel assumido pelo desejo homossexual se refere à sexualidade infantil e inconsciente, associada ao narcisismo ou àquilo que é próprio ou semelhante ao eu do sujeito. É nesse sentido que Freud afirma: "Enquanto foi sadio, também o Dr. Schreber, cujos delírios culminaram por uma fantasia de desejo de natureza inequivocamente homossexual, não havia, segundo afirmam todos, demonstrado quaisquer sinais de homossexualismo no sentido comum da palavra" (1911/1996, p.68). Para compreendermos melhor a relação entre homossexualismo e narcisismo, cabe frisar que este se refere à constituição do eu como imagem de si. Ele se dá a partir de uma identificação com a figura materna, em que a criança vê um igual, e que assume ao mesmo tempo o valor de objeto do desejo e de identificação.

Essa relação entre paranoia e homossexualismo também é abordada por Freud em Um Caso de Paranoia que Contraria a Teoria Psicanalítica da Doença (1915/1996), texto que, apesar do título, confirma o que foi dito anteriormente, ou seja, que o 
homossexualismo associado à paranoia não diz respeito ao homossexualismo manifesto, entendido no sentido comum do termo, mas a uma fixação infantil à imagem de si mesmo ou do mesmo. O texto relata o caso de uma jovem paranoica cujo objeto de amor sobre o qual incide a defesa e que, portanto, se transforma em perseguidor é, à primeira vista, uma pessoa do sexo masculino. Essa constatação iria de encontro às formulações de Freud referentes à relação entre paranoia e fixação homossexual, porém, como ele percebe na segunda entrevista com a jovem, havia uma fixação libidinal na figura materna, posteriormente deslocada para uma senhora idosa a quem era subordinada no trabalho. Notemos que o papel de perseguidor atribuído ao amante se deve ao lugar que ele ocupa em sua vida, determinado por uma rede de relações simbólicas. Em outras palavras, ele ocupa o lugar do pai, sendo que o lugar da mãe (origem da perseguição) é ocupado pela senhora com quem trabalhava. Não abordaremos os pormenores das relações entre narcisismo, identificação e escolha de objeto. Cabe frisar, entretanto, que a escolha homossexual, no sentido comum da palavra, também denominada inversão, apresentase apenas como possibilidade no processo constitutivo do sujeito.

De acordo com o que foi dito: esse fator constitutivo na formação do sujeito - e que, na maioria dos casos, também é transitivo - que é a escolha homossexual do objeto a partir da qual se pode passar a uma escolha heterossexual, possui, nos paranoicos, uma duração mais prolongada. Por esse motivo, muitas de suas características podem ser transportadas para estádios posteriores da vida do sujeito. A questão é: mesmo depois de terem sido superadas, essas tendências homossexuais não são deixadas de lado, mas simplesmente desviadas de seu objetivo sexual e empregadas em outras situações. Freud destaca a importância dessa libido para a constituição dos laços sociais, como: a amizade, a camaradagem e o amor à humanidade em geral. Entretanto, na medida em que os paranoicos têm no narcisismo seu ponto de fixação - a partir do qual pode operar-se uma disposição para uma enfermidade posterior - há o risco de que, ao encontrar um obstáculo à satisfação da libido, ocorra uma regressão que conduza a uma sexualização dos laços sociais, desfazendo, assim, as sublimações até então alcançadas. Esse processo, porém, diz respeito à formação dos sintomas, e sua possibilidade implica o momento anterior, que é a defesa contra uma representação incompatível.

\section{Considerações sobre a Verwerfung freudiana}

Considerando que até o presente momento utilizamos o termo recalque de forma indiscriminada, empregando-o tanto para as neuroses quanto para as psicoses, fazse necessário que apontemos a distinção entre o mecanismo de defesa neurótico e o mecanismo de defesa psicótico, denominado por Lacan foraclusão do Nome do Pai. Por mais que essa distinção seja fruto das investigações realizadas por Lacan, ela se tornou possível graças ao retorno empreendido por ele às obras de Freud. Lacan tomou de Freud um termo que até então passara despercebido em sua obra, a saber: o termo Verwerfung. Esse termo aparece em Freud com pouca frequência, e, de acordo com Maleval, não figura no índice da Gessammelte Werke nem no repertório da Standard Edition. É possível verificar que, ao longo da obra de Freud, não há uma delimitação precisa entre os termos Verdrängung e Verwerfung. Com esse intuito, nós nos apoiamos em Maleval, que realiza um comentário preciso sobre esse tema.

Nesse livro, Maleval refaz o percurso de Lacan - em sua abordagem estrutural das psicoses - e dedica o segundo capítulo a citar os textos de Freud em que aparece o termo Verwerfung. Dentre eles, estão: os Estudos 
sobre a Histeria (1895), em que Freud o utiliza como sinônimo de recalque, os Três Ensaios sobre a Teoria da Sexualidade (1905), em que é convocado para dar conta da recusa e da superação das fantasias incestuosas que emergem na puberdade, em Totem e Tabu (1913), situado no fundamento da consciência moral, entre outros, que, em decorrência da importância que possuem para nossa investigação, abordaremos a seguir. A questão é: embora Freud utilize o termo Verwerfung em diversos contextos e de modo pouco sistemático, ele aparece com alguma frequência em situações bem específicas, e, mesmo sendo empregado em certas ocasiões como sinônimo do recalque, designa geralmente uma forma de rechaço mais radical.

A primeira aparição do termo Verwerfung na obra freudiana, como foi dito no início do presente trabalho, se dá em As Neuropsicoses de Defesa (1894/1996). Nesse texto, ao se referir à confusão alucinatória, Freud fala de uma defesa mais poderosa em que o eu rejeita a ideia incompatível juntamente ao seu afeto. Essa passagem dá uma ideia da acepção em que Freud o utiliza: como ruptura mais radical que o recalque, e condizente com o sentido privilegiado por Lacan ao considerar a foraclusão. Outra passagem importante destacada por Maleval diz respeito à utilização do termo no texto intitulado História de uma Neurose Infantil (1918/1914), em que Freud relata o caso do Homem dos Lobos e a sua alucinação do dedo cortado. No seminário de 1954, Os Escritos Técnicos de Freud, Lacan cita uma passagem desse texto que deixa explícito que a Verwerfung não deve ser confundida com o recalque (Verdrängung): "Eine Verdrängung ist etwas anderes als eine Verwerfung". Lacan se lança contra a tradução francesa feita por Marie Bonaparte, que diz: "Um recalque é outra coisa que um julgamento que rejeita e escolhe" (1954/1975, p. 56). De fato, essa tradução é bem diferente da que podemos encontrar na tradução da Standard para o português, segundo a qual "uma repressão (recalque) é algo muito diferente de uma rejeição" (1918/1996, p.88). Lacan comenta essa passagem indicando que, na origem, “para que o recalque seja possível, é preciso que exista um para além do recalque, algo de derradeiro, já constituído primitivamente, um primeiro núcleo do recalcado, que não só não se revela mas que, por não se formular, é literalmente como se não existisse" (1954/1975, p.56). Embora essa passagem trate de um caso considerado por Freud como neurose obsessiva, ela reflete a preocupação de Lacan em diferenciar o recalque de uma recusa que deixa o significante de fora do simbólico, e que produz uma alucinação tal como as apresentadas em casos de psicose.

Feitos alguns comentários a respeito da Verwerfung freudiana, podemos retomar o Caso Schreber, e, a partir do que foi dito, repensar a projeção. Há nesse texto uma passagem em que Freud reformula o conceito de projeção. Para ele, não seria correto dizer que a representação suprimida é projetada para o exterior, e sim, que ela retorna de fora. Embora nesse texto Freud utilize o termo recalque ao se referir à paranoia, nessa passagem - que, aliás, possui um caráter de retificação -, podemos inferir, a partir da tradução, que o termo utilizado possui uma acepção distinta, como: suprimido ou abolido. Além disso, essa frase parece possuir um papel destacado na leitura que Lacan faz das obras de Freud, pois, se para este o que é abolido internamente retorna de fora, para aquele, o que é recusado no simbólico retorna no real. Em todo caso, devido à falta de acesso ao texto original, não podemos afirmar qual o termo utilizado por Freud nessa passagem, mas apenas inferir sua radicalidade, semelhante à atribuída a Verwerfung. 


\section{O elemento rechaçado na paranoia}

Ao considerar que nas psicoses a defesa consiste em uma ruptura mais radical, longe de esclarecer a questão, colocamos o problema de saber sobre o que ela incide. Em uma passagem de Neurose e Psicose, Freud afirma que: "as neuroses de transferência correspondem a um conflito entre o eu e o isso; as neuroses narcísicas, a um conflito entre o eu e o supereu, e as psicoses, a um conflito entre o eu e o mundo externo" (1924/1923, p.170). Cabe destacar que essa nova categorização das neuropsicoses não é desprovida de valor para a psicanálise, ao contrário, ela representa os últimos esforços de Freud em distribuir as afecções de acordo com os mecanismos de defesa. Além do mais, excetuando a subdivisão entre neurose narcísica (melancolia) e psicose (paranoia e esquizofrenia), ela nos permite conceber as estruturas clínicas praticamente do mesmo modo, e a partir dos mesmos termos em que hoje são concebidas na psicanálise: neurose, psicose e perversão.

Embora não empregue o conceito de supereu às psicoses - ao menos diretamente-, pouco antes de relacioná-lo à melancolia, Freud afirma: "a atitude do supereu deveria ser tomada em consideração - o que até aqui não foi feito - em toda forma de enfermidade psíquica (1923/1924, p.169)". Essa afirmação revela a preocupação de Freud, às voltas com a segunda tópica e com o supereu, porém, se esse conceito não é trabalhado com relação às psicoses, o mesmo não ocorre com o idealdo-eu. Além do mais, ainda que tais conceitos não se equivalham, em algumas passagens de À Guisa de Introdução ao Narcisismo (1914/1996), Freud utiliza a expressão ideal-do-eu em um sentido bem próximo ao atribuído, quinze anos depois, ao conceito de supereu - como instância crítica ou censora. Freud dedica toda a terceira seção desse texto a analisar a relação entre o delírio de estar sendo observado e o ideal-do-eu. Vejamos o que ele diz a respeito desse ideal.

De acordo com Freud, quando as moções pulsionais do sujeito entram em conflito com suas concepções culturais e éticas, o destino dessas moções é o recalque. Entretanto, tais concepções não se restringem a um conhecimento intelectual ou consciente, pois servem de parâmetro fundamental para a constituição do sujeito e atuam a partir da lógica inconsciente. Se em 1911 o recalque se dá a partir do eu, no texto sobre o narcisismo, Freud aponta a necessidade de maior precisão; trata-se de delimitar a condição que o possibilita. Esta, por sua vez, é a formação de um ideal-do-eu, a partir do qual o sujeito pode medir seu eu atual. Outro aspecto importante na formação desse ideal é o papel da libido narcísica a ele dirigida. Considerando a afirmação de que o mecanismo de defesa na paranoia consiste em retirar a libido investida nos objetos e reenviá-la ao eu, podemos pensar em uma proximidade entre o que Freud chama de objetos externos e o ideal-do-eu. De certa forma, esse ideal se constitui a partir de algo externo, como a influência crítica dos pais ou a opinião pública. Além disso, ao abordar o delírio de estar sendo observado, Freud afirma: "a sensação dos paranoicos de que todos os seus pensamentos são conhecidos, e de que todos os seus atos são vigiados ou supervisionados, se justifica pelo fato de que a crítica (ideal-do-eu) se apresenta de forma regressiva".

Vejamos em que consiste a regressão. Em um texto intitulado Suplemento Metapsicológico à Teoria dos Sonhos (1917/1996), Freud distingue duas formas de regressão: aquela que afeta o destino da libido (regressão topográfica) e aquela que afeta o desenvolvimento do eu. Essas duas formas de regressão podem dar-se simultaneamente, como ocorre nos sonhos. Neles, os investimentos que 
permanecem ligados aos restos diurnos préconscientes, ao receber um investimento do sistema inconsciente, são levados de volta às representações-de-coisa. Estas, por sua vez, sofrem regressão até o sistema consciente ou perceptual, em que o desejo onírico é experienciado de forma alucinatória. Nesse caso, podemos verificar que há tanto uma regressão topográfica, em que a libido faz um percurso avesso ao habitual, quanto uma regressão no desenvolvimento do eu, levando-o a uma forma de satisfação cuja estruturação lógica é anterior às formas de satisfação adquiridas. No caso dos sonhos, a segunda forma de regressão é consequência da primeira, pois, devido aos investimentos provenientes do inconsciente, as representações-de-palavra são substituídas por representações-de-coisa e alcançam o processo primário. No texto citado, Freud faz uma breve distinção entre a regressão nos sonhos e a esquizofrenia. Nesta, não há regressão topográfica, somente aquela que afeta o eu e as formas de satisfação. Se nos sonhos as representações-de-palavra são substituídas por representações-de-coisa, na esquizofrenia, são as próprias representaçõesde-palavra que passam a sofrer as influências do processo primário.

A regressão na esquizofrenia também é tratada no texto $O$ Inconsciente. Neste, a influência do processo primário sobre as representações-de-palavra podem chegar ao ponto "de uma única palavra assumir a representação de toda uma cadeia de pensamentos" (1915/2006, p.47). Vimos anteriormente que Freud define as entidades clínicas segundo o modo como se dão o processo de defesa e seu fracasso. Dessa forma, se a paranoia e a esquizofrenia são situadas no quadro das psicoses, é por haver algo em comum entre elas: em ambas, o mecanismo de defesa consiste em retirar a libido dos objetos externos. Podemos ponderar, portanto, que a descrição dos processos que ocorrem na esquizofrenia nos trazem elementos importantes para pensar sobre a paranoia. No texto citado, Freud destaca que a representação inconsciente abrange somente a representação-de-coisa, enquanto a representação pré-consciente abrange a representação-de-coisa mais a representação-de-palavra. Freud também enfatiza que o sistema inconsciente contém os primeiros e verdadeiros investimentos objetais. Tendo isso em vista, podemos compreender a afirmação de que, nas psicoses, a libido é retirada dos objetos. O que ocorre na verdade é que a libido proveniente do sistema inconsciente é retirada das representações-de-coisa, isto é, os verdadeiros investimentos objetais são desfeitos, permanecendo investidas somente as representações do pré-consciente. É nisso que consiste a regressão na esquizofrenia: a libido do inconsciente é retirada das representações-de-coisa e direcionada para as representações-de-palavra, por esse motivo, estas ficam submetidas ao processo primário. Nesse aspecto, o processo defensivo nas neuroses é radicalmente distinto do que ocorre nas psicoses. Nas primeiras, a representação-de-coisa tem o acesso negado à tradução, permanecendo recalcado no inconsciente; nas últimas, o que é rechaçado é a própria representação-de-coisa, sendo que o avanço do processo primário sobre as representações-de-palavra não faz parte da defesa em si, mas representa uma tentativa de cura por parte do sujeito.

Feitas algumas considerações sobre a regressão na esquizofrenia - processo que até certo ponto julgamos ser análogo ao da paranoia -, podemos buscar uma aproximação entre o que Freud denomina ideal-do-eu e o objeto externo sobre o qual incide a defesa paranoica. De acordo com o que foi dito no parágrafo anterior, arriscamo-nos a afirmar que: no mecanismo de defesa paranoico, assim como no esquizofrênico, a libido que provém do sistema inconsciente é retirada das representações-de-coisa. Não obstante, ainda 
que haja uma equivalência entre a libido ligada às representações-de-coisa e os ditos investimentos objetais, resta-nos considerar de que modo isso se relaciona com o idealdo-eu, ou com o supereu.

Jacques-Alain Miller (1991) faz um percurso que conduz do amor à morte e que, em suas palavras, é paralelo ao percurso de Freud entre Psicologia das Massas (1921/1996) e O Mal-estar na Civilização (1930/1996). No primeiro, a unificação simbólica dos grupos homogêneos se dá a partir da identificação com uma representação em comum, que, por se colocar no lugar do ideal-do-eu, possui papel de destaque nas relações amorosas entre os membros do grupo. Já no segundo se dá o oposto; nele se constata que aquilo que funciona no âmbito dos pequenos grupos não é válido para a sociedade como um todo.

Vejamos como Freud realiza esse percurso que vai do ideal-do-eu ao supereu, ou, nas palavras de Miller, do amor à morte. Para Freud, a consciência moral não é primária ou inata, mas se constitui a partir de um operador que está fora. Nesse sentido, devemos considerar as condições a partir das quais ele considera a relação do sujeito com o Outro. Segundo Miller (1991), são elas: o desamparo infantil, a dependência com relação às outras pessoas e a terceira - que é consequência das demais - a angústia da perda do amor. Tais condições se referem a um sujeito inserido no campo da linguagem, e implicam sempre um endereçamento ao Outro. A questão, entretanto, é perceber como elas possibilitam a formação do supereu. Vimos que, em consequência do desamparo e da dependência, surge a angústia da perda do amor, isto é, uma demanda de amor endereçada àquele que cuida. A partir da demanda de amor, pode-se pensar sobre a renúncia pulsional, pois, caso contrário, os pais poderiam irritar-se. Como diz Miller: "Havendo marmelada na cozinha, porque não comê-la toda?" O problema é que o sujeito passa a gozar na renúncia 'não só não vai comer marmelada, mas não vai comer nada'" (1991, p. 56). Em princípio se renuncia à satisfação para não perder o amor do Outro. Trata-se, neste caso, de uma moralidade externa em que toda ameaça se refere à perda do amor, porém, desde que o Outro não saiba, não há problema algum em comer a marmelada toda. Entretanto, em um segundo momento, Freud introduz a noção de introjeção, por meio da qual aquilo que é externo, como a influência crítica dos pais, se torna uma representação interna. Esse processo simbólico, de inscrição de um significante, está na origem do supereu, que, por estar dentro, sabe de todos os desejos do sujeito, causa o sentimento de culpa e exige que se renuncie cada vez mais, extraindo daí o seu gozo.

Não podemos perder de vista que, ao abordar questões referentes ao supereu, nosso intuito era aproximá-lo do elemento sobre o qual incide a defesa paranoica. Essa aproximação, por sua vez, só se torna possível à medida que traçarmos as distinções entre o modo como ele atua nas neuroses e os processos análogos que ocorrem nas psicoses. Se nas neuroses há um conflito entre o eu e o isso, é porque o eu se coloca a serviço do supereu. Isso é possível devido ao fato de que as forças atuantes no supereu são extraídas do isso, ou seja, o amor que conduz à pulsão de morte não é senão a libido proveniente do isso investida nas figuras parentais, responsáveis pelos cuidados com a criança assim como por transmitir a lei. $\mathrm{Na}$ paranoia, por sua vez, a relação com a lei se dá de forma bem diversa. Nas neuroses, por mais que o eu esteja a serviço do supereu, à medida que este deriva dos investimentos do isso, ambos se satisfazem, ainda que parcialmente, daí a afirmação de Freud de que, nas neuroses, a defesa em si não é patológica, mas seu fracasso ou retorno como elemento estranho ao sujeito. Nas psicoses, a própria defesa é patológica, pois há nelas uma recusa das influências externas, ficando o eu sob o domínio restrito do isso. 
Nesse aspecto, talvez seja interessante considerar a distinção traçada por Freud entre psicose e neurose narcísica. Por que o conflito nas neuroses narcísicas se dá entre o eu e o supereu, e, nas psicoses, entre o eu e a realidade externa? Não seria por haver na melancolia (neurose narcísica) uma introjeção da lei, um processo em que as influências externas culminam na formação de um supereu constituinte do sujeito? O que nos leva a pensar assim, além da distinção feita em Neurose e Psicose (1923/1924), é o fato de, em Luto e Melancolia (1915/1917), Freud se referir constantemente à autorecriminação melancólica. É certo que, em 1896, nas Observações Adicionais sobre as Neuropsicoses de Defesa, Freud utiliza uma expressão bem próxima ao se referir à paranoia: nesta, "a defesa fracassa por completo, e a auto-acusação original,... retorna em sua forma inalterada" (1896/1996, p. 171). Não obstante, em 1911, ele acrescenta que aquilo que foi abolido - a crítica ou acusação - retorna de fora, ideia que é reafirmada nos textos de 1924.

Nosso intuito de aproximar o supereu do elemento sobre o qual incide a defesa paranoica conta com argumentos há muito apontados em nossas digressões, restandonos agora apenas um forçamento de síntese. Como foi dito anteriormente, o mecanismo de defesa, na paranoia, refere-se a um rechaço mais radical. Trata-se, por exemplo, do termo Verwerfung empregado por Freud, ainda que de forma não sistemática. Essa radicalidade também pode ser inferida da tradução Standard; mesmo não havendo referências aos termos empregados no original, muitas vezes, quando a defesa paranóica é tratada, os termos que aparecem são: abolido, suprimido ou rejeitado. Esse apontamento nos permite pensar sobre a diferença entre o mecanismo de defesa nas psicoses e nas neuroses. Se nestas a representação incompatível permanece no inconsciente tendo o acesso barrado à consciência, naquelas, a representação incompatível é deixada de fora, ou seja, na paranoia não ocorre o deslocamento do afeto de uma representação à outra (formação de símbolo); o que ocorre é que os investimentos libidinais nas representações-de-coisa são desfeitos e seu afeto é redirecionado para o eu.

Foi o que vimos ao tratar a regressão na esquizofrenia. A retirada de afeto das representações inconscientes faz com que elas sejam experienciadas de forma regressiva, por meio da alucinação. Não obstante, devemos destacar que não basta que haja alucinação para dizer que algo retorna de fora ou que possui um caráter de certeza para o sujeito. Aliás, o que determina esse caráter é o mecanismo responsável pela alucinação. Quando esta ocorre na histeria, por exemplo, é devido à ligação da representação alucinada com uma cadeia de representações inconscientes, e em consequência do sobreinvestimento que daí provêm. Na paranoia, por sua vez, aquilo que retorna de fora não possui nenhuma articulação com as representações do sujeito - sejam elas conscientes ou inconscientes. É nesse sentido que o caráter de certeza ou de exterioridade que a alucinação representa é proporcional ao estranhamento que ela causa. Vimos que aquilo que retorna na paranoia possui um caráter de crítica ou de acusação ao sujeito. Sendo assim, podemos afirmar que o elemento rechaçado na paranoia é a própria influência crítica dos pais, representação que, ao ser introjetada, permitiria a formação de um supereu.

\section{Conclusão}

Neste percurso que realizamos, fica claro o esforço de Freud em aliar uma interrogação teórica aos impasses que a clínica apresenta. A cada momento em que era interrogado sobre a questão das psicoses, Freud, sem recuar, acabava refinando a teoria psicanalítica e 
assentando as bases de uma clínica cada vez mais pertinente. É justamente por extrair lições da experiência que Freud, em seu esforço nosográfico em discernir as diversas modalidades de apresentação do sofrimento psíquico, pôde construir conceitos que nos permitem uma orientação clara dentro do campo da clínica. Em primeiro lugar, a orientação em relação à etilogia do sofrimento psíquico: Freud, no desenrolar de seu trabalho, abandona a determinação biológica do sofrimento psíquico e demonstra a causalidade psíquica deste. Isso teve como impacto o abandono da primeira nosografia freudiana: aquela entre neuroses atuais e neuroses de defesa. Se todas as psicopatologias são da ordem da defesa, possuindo um caráter misto, resta a Freud buscar elementos para melhor distinguir nosograficamente as estruturas.

Inicialmente, a paranoia faz conjunto com a histeria e a neurose obsessiva, e, assim como estas, é classificada simplesmente como neuropsicose. No entanto, mesmo nesse momento já vemos distinções importantes entre elas serem trazidas à discussão: se as três (histeria, obsessões e paranoia) em um primeiro momento podem forjar formações de compromisso, a paranoia não faz formação de símbolo, o que força Freud a considerar não somente a magnitude do seu fracasso como também a importância do mecanismo de projeção. Além do mais, com a formação de impasses clínicos e teóricos, foi possibilitado o aparecimento de novos conceitos que tornaram mais precisa a especificidade da paranóia na obra freudiana. Conceitos tais como o de narcisismo e recalque primário, assim como as considerações metapsicológicas sobre os processos defensivos, permitiram a elaboração de um mecanismo específico para o rechaço na paranoia. Assim, a paranoia deixa de fazer par com a histeria e a neurose obsessiva, que passam para o campo da neuroses, e passa a fazer par com a esquizofrenia no conjunto das psicoses. Seu modelo defensivo, assim, ganha mais precisão: não se trata necessariamente de um recalque, mas de um rechaço que produz não uma projeção, e sim, uma regressão à fixação narcísica. Desse modo, podemos extrair como resultado que a vulgata de que Freud pouco produziu sobre as psicoses não se sustenta, o que faz com que sua obra se torne matriz de pensamento também sobre as psicoses.

\section{Roberto Calazans}

Doutor em Teoria Psicanalítica pela Universidade Federal do Rio de Janeiro; Bolsista em Produtividade Nível 2 CNPq. Professor Associado I do Programa de Pós-Graduação em Psicologia da Universidade Federal de São João Del-Rei, São João Del-Rei-MG - Brasil

E-mail: roberto.calazans@gmail.com

Leandro Nogueira dos Reis

Mestre em Psicologia pela Universidade Federal de São João Del-Rei, São João Del-Rei - MG - Brasil.

E-mail: Inogueirareis@gmail.com

Endereço para envio de correspondência:

Praça Dom Helvécio, 74. Bairro Dom Bosco. CEP: 36301-160. São João Del-Rei, MG.

Recebido 06/11/2011, 1ㅍ Reformulação 30/08/2013, Aprovado 29/11/2013. 
Freud, S. (1918). História de uma neurose infantil. In Edição standard brasileira das obras completas psicológicas de Sigmund Freud. Rio de Janeiro: Imago. (Trabalho original publicado em 1914)

Freud, S. (1924). Neurose e psicose. In Edição standard brasileira das obras completas psicológicas de Sigmund Freud. Rio de Janeiro: Imago. (Trabalho original publicado em 1923)

Freud, S. (1950). Projeto para uma psicologia científica. In Edição standard brasileira das obras completas psicológicas de Sigmund Freud. Rio de Janeiro: Imago. (Trabalho original publicado em 1895)

Freud, S. (1996). As neuropsicoses de defesa. In Edição standard brasileira das obras completas psicológicas de Sigmund Freud. Rio de Janeiro: Imago. (Trabalho original publicado em 1894)

Freud, S. (1996). Rascunho H. In Edição standard brasileira das obras completas psicológicas de Sigmund Freud. Rio de Janeiro: Imago. (Trabalho original publicado em 1895)

Freud, S. (1996). Rascunho K. In Edição standard brasileira das obras completas psicológicas de Sigmund Freud. Rio de Janeiro: Imago. (Trabalho original publicado em 1896)

Freud, S. (1996). Observações adicionais sobre as neuropsicoses de defesa. In Edição standard brasileira das obras completas psicológicas de Sigmund Freud. Rio de Janeiro: Imago. (Trabalho original publicado em 1896)

Freud, S. (1996). Notas psicanalíticas sobre um relato autobiográfico de um caso de paranóia. In Edição standard brasileira das obras completas psicológicas de Sigmund Freud. Rio de Janeiro: Imago. (Trabalho original publicado em 1911)

Freud, S. (1996). Um caso de paranóia que contraria a teoria psicanalítica da doença. In Edição standard brasileira das obras completas psicológicas de Sigmund Freud. Rio de Janeiro: Imago. (Trabalho original publicado em 1915)
Freud, S. (1996). Suplemento metapsicológico à teoria dos sonhos. In Edição standard brasileira das obras completas psicológicas de Sigmund Freud. Rio de Janeiro: Imago. (Trabalho original publicado em 1917)

Freud, S. (1996). Análise terminável e interminável. In Edição standard brasileira das obras completas psicológicas de Sigmund Freud. Rio de Janeiro: Imago. (Trabalho original publicado em 1937).

Freud, S. (2004). À guisa de introdução ao narcisismo. In Obras psicológicas de Sigmund Freud. Rio de Janeiro: Imago. (Trabalho original publicado em 1914)

Freud, S. (2004a). Pulsões e destinos da pulsão. In Obras psicológicas de Sigmund Freud. Rio de Janeiro: Imago. (Trabalho original publicado em 1915)

Freud, S. (2004b). O recalque. In Obras psicológicas de Sigmund Freud. Rio de Janeiro: Imago. (Trabalho original publicado em 1915)

Freud, S. (2006). O inconsciente. In Obras psicológicas de Sigmund Freud. Rio de Janeiro: Imago. (Trabalho original publicado em 1915)

Lacan, J. (1975). O seminário. Livro 1: os escritos técnicos de Freud. Rio de Janeiro: Jorge Zahar Editor. (Trabalho original publicado em 1954).

Maleval, J. C. (2002). La forclusíon del nombre del padre. Buenos Aires: Paidós.

Miller, J. A. (1991). Logicas de la vida amorosa. Buenos Aires: Ediciones Manantial SRL. (Trabalho original publicado em 1989)

Simanke, R. (1994). A formação da teoria freudiana das psicoses. Rio de Janeiro: Editora 34 